\title{
Are synchronised swimmers at risk of amenorrhoea?
}

\author{
R Ramsay, R Wolman
}

\begin{abstract}
Objective-Synchronised swimming is a sport that shares certain characteristics with other aesthetically pleasing sports such as gymnastics and dance. The purpose of this investigation was to ascertain whether the highest ranked synchronised swimmers in the United Kingdom experience menstrual abnormalities, a common medical problem seen in these related activities.

Methods-Twenty three members of the Great Britain synchronised swimming squad completed a questionnaire on menstrual history. Body composition and $V_{2}$ MAX were measured in the laboratory during regular physiological screening. Results-Three of the 23 subjects were oligomenorrhoeic and none were amenorrhoeic. All were postmenarchal. Mean estimated body fat percentage was $23 \%$, and mean $\mathrm{Vo}_{2} \mathrm{MAX}$ was $47.2 \mathrm{ml} / \mathrm{kg} / \mathrm{min}$.

Conclusions-It appears that synchronised swimmers in the United Kingdom are relatively protected from menstrual disturbances for reasons that cannot be explained in isolation.

(Br f Sports Med 2001;35:242-244)
\end{abstract}

Keywords: synchronised swimming; amenorrhoea; menarche

Synchronised swimming is a sport that requires a high level of aerobic and anaerobic conditioning combined with grace and agility. The physiological and aesthetic demands are comparable with those of gymnastics, ice skating, and dance. Athletes in these types of sport are often under pressure to maintain unrealistically low body weight. This can lead to the development of disordered eating and amenorrhoea, the incidence of which is particularly high in gymnasts and dancers. ${ }^{1}$ By contrast, swimmers are relatively protected from developing amenorrhoea for reasons not fully understood. ${ }^{1}$ However, the incidence among synchronised swimmers is unknown. Furthermore, delayed menarche, an additional risk factor for developing secondary amenorrhoea, ${ }^{2}$ although prevalent in some sports has not been assessed in synchronised swimming.

Amenorrhoea is a major risk factor for the development of osteopenia and osteoporosis. ${ }^{3}$ We therefore undertook a study to assess the incidence of menstrual abnormalities in synchronised swimming in view of the potential damaging effect on the skeleton.
Methods

Twenty three members of the Great Britain senior (seven) and junior (16) synchronised swimming squads for 2000-2001 (mean (SD) age 17.1 (1.9) years) were sent a "menstrual questionnaire" (adapted from a questionnaire previously used with other elite female athletes $\left.{ }^{1}\right)$. The questionnaire assessed aspects of training, the menarche, use of oral contraceptives, the current menstrual cycle, previous menstrual cycles, and the occurrence of any injuries. Amenorrhoea was defined as no more than one period in the six months before the study. Oligomenorrhoea was defined as a cycle length of greater than 35 days and eumenorrhoea as a cycle length of less than 35 days.

Twenty one of the 23 swimmers (mean (SD) height 1.65 (0.07) m; body mass 55.7 (6.9) kg) attended the British Olympic Medical Centre for physiological testing the following month. Physiological assessment included measurement of body density, estimated from the sum of four skinfold sites ${ }^{4}$ and estimated percentage body fat. ${ }^{5}$ Fat mass, fat free mass, and body mass index (weight $(\mathrm{kg}) /$ height $(\mathrm{m})^{2}$ ) were also calculated. Aerobic capacity $\left(\mathrm{VO}_{2} \mathrm{MAX}\right)$ was measured using a continuous incremental protocol $(1.1 \mathrm{~km} / \mathrm{h}$ increments every minute) on a treadmill. Expired air was analysed breath by breath using an Oxycon Alpha online gas analysis system (Jaeger-Mihnhardt, Hoechberg, Germany). Maximum heart rate (beats/ min) was measured using a Polar Sports Tester heart rate monitor (Electro Oy, Kempele, Finland).

\section{Results}

Synchronised swimming training began at a mean age of 8.4 (1.5) years. Before they started synchronised swimming training, $65 \%$ of the group had been involved with swimming, $56.5 \%$ with gymnastics, and 30\% each with ballet and dance. Swimmers were currently performing 12 (2) synchronised swimming sessions a week. All 23 swimmers were postmenarchal. The mean age of the menarche was 13.7 (0.88) years (range 11.8-15.9).

Five of the group were taking the oral contraceptive pill (four of whom attended for physiological testing). Fifteen of the group had menses of normal frequency (14 of whom attended for physiological testing), and three presented with oligomenorrhoea. None of the group were amenorrhoeic.

Table 1 gives data on body composition and $\mathrm{VO}_{2} \mathrm{MAX}$. Results of single factor analysis of variance showed there to be no differences between groups $(\mathrm{p}<0.05)$. 
Table 1 Physiological information on the synchronised swimmers by menstrual group

\begin{tabular}{|c|c|c|c|c|}
\hline & $\begin{array}{l}\text { Whole squad } \\
(n=21)\end{array}$ & $\begin{array}{l}\text { Oral contraceptive } \\
\text { users }(n=4)\end{array}$ & $\begin{array}{l}\text { Oligomenorrhoeic } \\
(n=3)\end{array}$ & $\begin{array}{l}\text { Eumenorrhoeic } \\
(n=14)\end{array}$ \\
\hline \multicolumn{5}{|c|}{ Sum skinfolds (mm) } \\
\hline Mean & 41.0 & 43.0 & 37.3 & 41.3 \\
\hline SD & 8.6 & 11.5 & 0.6 & 8.9 \\
\hline \multicolumn{5}{|c|}{$\%$ Body fat } \\
\hline Mean & 23.0 & 23.6 & 22.0 & 23.1 \\
\hline SD & 3.0 & 3.8 & 0.2 & 3.2 \\
\hline \multicolumn{5}{|c|}{ Body mass index } \\
\hline Mean & 20.4 & 20.7 & 19.5 & 20.5 \\
\hline SD & 1.5 & 1.4 & 0.7 & 1.6 \\
\hline \multicolumn{5}{|c|}{$\mathrm{VO}_{2} \operatorname{MAX}(\mathrm{ml} / \mathrm{kg} / \mathrm{min})$} \\
\hline Mean & 47.2 & 48.9 & 47.6 & 46.6 \\
\hline SD & 3.8 & 4.0 & 2.2 & 4.1 \\
\hline
\end{tabular}

Traumatic fractures had previously occurred in four swimmers during childhood and in one at the age of 14 .

\section{Discussion}

Athletic amenorrhoea was first recognised in the late $1970 \mathrm{~s}^{6}$ and was thought to be due to the effect of intensive endurance exercise and poor dietary intake. The amenorrhoea, which is due to hypothalamic dysfunction, ${ }^{7}$ was initially thought to be relatively benign, but by the middle of the 1980s it became clear that the associated fall in bone density was irreversible and leads to osteoporosis. ${ }^{3}$ These connections created the "female athlete triad", a syndrome that comprises disordered eating, amenorrhoea, and osteoporosis. ${ }^{8}$

The risk of developing the triad occurs in sports in which low body weight is perceived to confer an advantage to performance (distance running), in those in which performance is subjectively measured (gymnastics, dance, figure skating), and in those using weight categories for competition (lightweight rowing, martial arts). ${ }^{9}$ Furthermore, when heavy training in these sports begins in childhood, there is a higher incidence of delayed menarche. This is seen in gymnastics, dance, and even swimming. ${ }^{10-12}$ Delayed menarche is also known to be a risk factor for osteoporosis in later life. ${ }^{13}{ }^{14}$ Whether heavy training itself is the cause of delayed menarche or whether women who are constitutionally destined to have later menarche are at a competitive advantage and are therefore drawn to and continue to participate in competitive sport ${ }^{15}$ remains unclear.

Synchronised swimmers share certain physiological characteristics with gymnasts and dancers, who have a high incidence of amenorrhoea. However, they also share other features with conventional swimmers, who have a low incidence. This study therefore attempted to assess the risk of developing menstrual abnormalities in this group of athletes. Only three of the 18 subjects not taking the oral contraceptive had infrequent periods. This represents an incidence similar to that seen in conventional swimmers and much lower than that seen in gymnasts. ${ }^{1}$ Furthermore, the mean age of the menarche in this group (13.7 years) is midway between the age seen in non-athletes (12.8 years $)^{16}$ and in other Olympic athletes (14.8 years). ${ }^{17}$ There is therefore little evidence from this study that synchronised swimming training significantly increases the risk of menstrual abnormalities.
There are currently three main theories on why swimmers seem to be relatively protected from developing menstrual abnormalities. The first is that immersion in cool water during exercise may allow swimmers to gain better control of their core temperature than runners or dancers. This may cause less disruption to hypothalamic function and hence allow normal menstruation to be preserved. ${ }^{18}$ Furthermore, a high body temperature may inhibit the binding of sex steroids to plasma protein, ${ }^{19}$ causing an increase in the metabolically active free fraction of hormones. ${ }^{20}$

Secondly, conventional swimmers have a relatively high level of body fat, ${ }^{21}$ as do the synchronised swimmers in this study (mean 23\%), compared with amenorrhoeic athletes (usually less than $19 \%$ ). ${ }^{1}$ This may be the result of a natural selection process, greater body fat allowing swimmers to float higher in the water, thereby improving streamlining and reducing drag. The increased buoyancy may also be advantageous in synchronised swimmers. ${ }^{22} 23$ High body fat protects against developing amenorrhoea.

Thirdly, it is possible that menstrual function is preserved in this group because of a reasonable balance between dietary intake and energy expenditure from training. It is likely that synchronised swimmers do not engage in the combination of "disordered eating" and intensive training to the same extent as other athletes suffering with amenorrhoea.

The aerobic capacity of the synchronised swimmers was found to be lower (47.2 $\mathrm{ml} / \mathrm{kg} / \mathrm{min}$ ) than seen in athletes from aerobic sports but similar to the values seen in American and Canadian national level synchronised

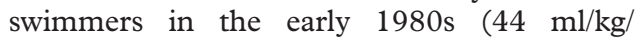
min). ${ }^{23}{ }^{24}$ These athletes were tested in similar conditions to those in the present study. However, in a more recent investigation, the mean aerobic power of the Japanese national team (tested in a swimming flume) was higher (50.8 (2.9) $\mathrm{ml} / \mathrm{kg} / \mathrm{min}){ }^{25}$ Although it is difficult to examine the effect of training on menstrual function in isolation, it remains to be seen whether an increase in the aerobic training intensity of the current cohort of synchronised swimmers would lead to an increased incidence of menstrual irregularity.

This study suggests that elite level synchronised swimmers in the United Kingdom are not at risk of developing menstrual abnormalities and consequently are unlikely to have reduced bone mineral density. However, their training (mainly non-weight bearing) probably confers no advantage to bone density.

\footnotetext{
1 Wolman RL, Harries MG. Menstrual abnormalities in elite athletes. Clin Sports Med 1989;1:95-100.

2 Noakes TD, Van Gend M. Menstrual dysfunction in female athletes. A review for clinicians. $S$ Afr Med $\mathcal{F}$ 1988;73:350-5

3 Drinkwater BL, Nilson K, Chestnut $\mathrm{CH}$, et al. Bone mineral content of amenorrhoeic and eumenorrhoeic athletes. $N$ Engl f Med 1984;311:277-81.

4 Durnin JV, Womersley J. Body fat assessed from total body density and its estimation from skinfold thickness: measurements on 481 men and women aged from 16 to 72 measurements on 481 men and

5 Siri WE. The gross composition of the body. In: Tobias CA, Siri WE. The gross composition of the body. In: Tobias CA,
Lawrence JH, eds. Advances in biological and medical physics. Lawrence JH, eds. Advances in biological and

6 Feicht CB, Johnson TS, Martin BJ, et al. Secondary amenorrhoea in athletes. Lancet 1978;2:1145-6.
} 
7 Veldhuis JD, Evans WS, Demers LM, et al. Altered neuroendocrine regulation of gonadotrophin secretion in women dis-

8 Yeager KK, Agostini R, Nattiv A, et al. The female athlete triad: disordered eating, amenorrhoea, osteoporosis [commentary]. Med Sci Sports Exerc 1993;25:775-7.

9 West RV. The female athlete: the triad of disordered eating, amenorrhoea and osteoporosis. Sports Med 1998;2:63-71.

10 Georgopoulos N, Markou K, Theodoropoulou A, et al. Growth and pubertal development in elite female rhythmic gymnasts. F Clin Endocrinol Metab 1999;84:4525-30.

11 Warren MP. The effects of exercise on pubertal progression and reproductive function in girls. $\mathcal{F}$ Clin Endocrinol Metab 1980;51:1150-7.

12 Constantini NW, Warren MP. Menstrual dysfunction in swimmers: a distinct entity. F Clin Endocrinol Metab 1995;80:2740-4

13 Cooper GS, Sandler DP. Long term effects of reproductiveage menstrual cycles patterns on peri- and post menopauage menstrual cycles patterns on peri- and post m

14 Keay N, Fogelman I, Blake G. Bone mineral density in professional female dancers. Br F Sports Med 1997;31:143profes.

15 Chen EC, Brzyski RG. Exercise and reproductive dysfunction. Fertil Steril 1999;71;1-6.

16 Lebrun CM. The female athlete. In: Harries M, ed. Oxford textbook of sports medicine. Oxford: Oxford University Press, 1998:743-79.
17 Malina RM. Menarche in athletes, a synthesis and hypothesis. Ann Hum Biol 1983;10:1-24.

18 Loucks AB, Horvath SM. Athletic amenorrhea: a review. Med Sci Sports Exerc 1985;17:56-72.

19 Lata GF, Hu HK, Bagshaw G, et al. Equilibrium and kinetic characteristics of steroid interactions with human plasma sex binding protein. Arch Biochem Biophys 1980;199:220-7.

20 Arena B, Maffulli N, Maffulli F, et al. Reproductive hormones and menstrual changes with exercise in female athletes. Sports Med 1995;19:278-87.

21 Jang KT, Flynn MG, Costill DL, et al. Energy balance in competitive swimmers and runners. fournal of Swimming Research 1987;3:19-23.

22 Nakamura Y, Takamoto M, Mutoh Y. Physical composition and characteristics of muscle strength of synchronised and characteristics of muscle strength of synchronised 52.

23 Roby FB, Buono MJ, Constable SH, et al. Physiological characteristics of champion synchronised swimmers. Physician and Sportsmedicine 1983;11:136-47.

24 Poole GW, Crepin BJ, Seivigny, M. Physiological characteristics of elite synchronised swimmers. Can $\mathcal{F}$ Appl Sport Sci 1980;5:156-60.

25 Yamamura C, Zushi S, Takata K, et al. Physiological characteristics of well-trained synchronised swimmers in relation to performance scores. Int $\mathcal{F}$ Sports Med 1999;20:246-51.

\section{Take home message}

Although synchronised swimmers share certain characteristics with other sportswomen who have a high risk of developing the "female athlete triad", this study shows that synchronised swimmers are not at risk from developing this syndrome.

\section{Commentary}

Female athletic activities have now achieved widespread social acceptance. Although one of the greatest public health problems is the lack of exercise, exercise induced menstrual abnormalities can produce serious life threatening abnormalities as well as subfertility. It is accepted that different levels of exercise as well as different types of exercise can cause different effects on the hypothalamic pituitary gonadal axis.

This paper by Ramsay and Wolman helps by providing another small piece of the jigsaw in this fascinating area. The authors do allude to body mass, but the role that this has is still under debate. There appears to be no critical fatness threshold for the maintenance of menses that is applicable to athletes in general. ${ }^{1}$ A popular theory has maintained that low body fat is the cause of amenorrhoea and $22 \%$ body fat is thought to be necessary to maintain regular menstrual cycles. This does need to be challenged as regular cycles are seen in athletes with less than $17 \%$ body fat, and amenorrhoeic and eumenorrhoeic runners have been found to have similar percentages of body fat. Leptin, a protein that is encoded in the obese gene and expressed in adipocytes, may have a role as a metabolic signal between body composition and reproductive maturation and regularity.

Protein, fat, total energy intake, and training regimens may also play a role in discipline specific menstrual irregularities. Immersion in water may also have a specific effect on prolactin levels, with breast support being given to prevent a simulated suckling response. This has been demonstrated in pregnancy. ${ }^{2}$

The authors do need to be congratulated on keeping this important debate going.

MICHAEL DOOLEY

Winterbourne Hospital, Herringston Road Dorchester DT1 2AR, UK gynaecology2@hotmail.com

1 Chen EC, Brzyski RG. Exercise and reproductive dysfunction. Fertil Steril 1999;71:1-6.

2 Katz VL, McMurray R, Turnbull CD, et al. The effects of immersion and exercise on prolactin during pregnancy. Eur $\mathcal{F}$ Appl Physiol 1990;60:191-3. 